\title{
Análise comparativa entre um fogão solar do tipo parabólico e fogão solar do tipo caixa
}

\author{
Luiz José de Bessa Neto ${ }^{[1]}$, Francisco José Sombra Jr ${ }^{[2]}$, Fabiana Karla de O. M. Varella Guerra ${ }^{[3]}$, \\ Antônio Eduardo de O. Carvalho ${ }^{[4]}$ e Elaine Priscila Fontes Da Silva ${ }^{[5]}$ \\ [1] Universidade Federal Rural do Semi-árido; luizjbessa@outlook.com \\ [2] Universidade Federal Rural do Semi-árido; fjsombrajunior@yahoo.com.br \\ [3] Universidade Federal Rural do Semi-árido; fkv@ufersa.edu.br \\ [4] Universidade Federal Rural do Semi-árido; eduardocarvalho371@ gmail.com \\ ${ }^{[5]}$ Universidade Federal Rural do Semi-árido; priscilarsrn@ @otmail.com
}

Recebido: 08/06/2019;

Aceito: $13 / 08 / 2019$;

Publicado: 07/10/2019.

Resumo: Na busca do desenvolvimento de projetos voltados à utilização de energia limpa e renovável, a energia solar vem ganhando destaque nos últimos anos. Essa configura-se como uma fonte de energia abundante e inesgotável, uma vez que é proveniente de fenômenos naturais e possibilita a captação e conversão em outras formas de energia. Estudos relatam a importância e viabilidade da utilização de muitos equipamentos, dentre estes, o fogão solar para cocção de vários alimentos. O presente trabalho apresenta o desenvolvimento de dois protótipos de fogões solares, um do tipo parabólico e outro do tipo caixa, e tem como objetivo realizar uma análise comparativa do desempenho no processo de cocção de duas porções de arroz, considerando-se as observações concernentes aos valores de temperatura, a irradiância e o tempo de cozimento entre os modelos estudados. Com o desenvolvimento do vigente trabalho, verificou-se que o fogão solar do tipo caixa apresentou melhor resultado do que o fogão solar tipo parabólico, nas condições à que foram submetidos.

Palavras-chave: Energia solar; Eficiência térmica; Fogão solar; Cocção de alimentos

\section{INTRODUÇÃO}

$\mathrm{O}$ aproveitamento da energia gerada pelo sol é inesgotável na escala terrestre de tempo, tanto como fonte de calor quanto de luz, e é considerada uma das alternativas energéticas mais promissoras no mundo. E quando se fala em energia, deve-se lembrar de que o sol é responsável pela origem de praticamente todas as outras fontes de energia. Em outras palavras, as fontes de energia são, em última instância, derivadas da energia do Sol. Não obstante, com o crescente aumento da população mundial e, consequentemente, do consumo de energia elétrica no mundo, cada vez mais se torna importante o uso de fontes de energias alternativas, visto que com o passar do tempo haverá cada vez mais dificuldade em se obter os recursos necessários para a geração de energia por meio das fontes energéticas convencionais esgotáveis, como, por exemplo, os combustíveis fósseis.

O presente modelo de crescimento econômico gerou enormes desequilíbrios, pois se por um lado nunca houve tanta riqueza e fartura no mundo, por outro lado a miséria, a degradação ambiental e a poluição aumentam diariamente. Diante desta constatação, surgiu a ideia do desenvolvimento sustentável, buscando conciliar o desenvolvimento econômico com a preservação ambiental, não só para essa geração como também para a futura. Esse desenvolvimento promove o chamado ecocapitalismo com a ampliação de tecnologias limpas, redução de lixo, reciclagem com coleta seletiva, reutilização de águas, enfim, o desenvolvimento da humanidade em harmonia com a natureza [1].

Nas últimas décadas, têm se tornado indispensável estudos que visem o melhor aproveitamento das fontes alternativas de energia, diminuindo, dessa forma, a dependência do petróleo como fonte principal e reduzindo os impactos ambientais. Nesse sentido, esforços significativos estão sendo direcionados para o aproveitamento 
de outras fontes de energia como, por exemplo, a energia solar, que leva em consideração além da eficiência energética, o apelo ambiental a qual o mundo está inserido [2].

A energia solar é uma fonte abundante e disponível a todos, que pode ser aproveitada de diversas maneiras como geração de eletricidade; desidratação de alimentos; aquecimento, desinfecção e destilação de água e cocção. Este último tem como aspecto primordial a viabilização de energia limpa e renovável para a sociedade, combatendo os danos ecológicos causados pela utilização em larga escala de lenha para o cozimento de alimentos, tendo utilização em países tropicais com altos índices de radiação solar, possuindo financiamento de ONGs por todo o mundo com objetivo de atingir a população de baixa renda [3].

Uma das aplicações mais práticas e econômicas da energia solar é o uso de fogões solares para cocção de alimentos, sendo atualmente bem utilizada em países como índia, China e Peru, entre outros. Nos dois primeiros, o número de fogões solares em operação supera a casa das 100.000 unidades [4]. No Brasil, o principal emprego dos fogões solares é na zona rural das regiões áridas e semiáridas onde a extração de lenha para obtenção de energia térmica assume valores significativos, causando o desmatamento da caatinga [1].

Ante o exposto, o presente trabalho tem como objetivo realizar uma análise comparativa do desempenho no processo de cocção dos alimentos de dois protótipos de fogões solares, sendo um do tipo parabólico e outro do tipo caixa, considerando-se as observações concernentes aos valores de temperatura, à irradiância e ao tempo de cozimento dos modelos estudados.

\section{FOGÃO}

Os fogões solares surgem como resposta ao uso dos fogões convencionais que utilizam gás ou lenha na cocção de alimentos, já que em termos globais a queima da lenha utilizada para essa finalidade atinge cerca de 2,5 bilhões de pessoas, dos quais 23 milhões são brasileiros, segundo dados de [5]. De acordo com [6], esses fornos solares encontram ampla aplicação em todo o planeta, essencialmente na Ásia e África, com destaque para a Índia e China, visto que são os países que mais tem investido em programas sociais que viabilizam a construção de fogões solares à baixo custo. Nesse viés, segundo [7], essa tecnologia visa utilizar a energia proveniente do sol, através dos raios solares em forma de calor para cozinhar ou pasteurizar os alimentos. $\mathrm{Na}$ literatura perduram três tipos de fogões solares: fogão solar do tipo painel, fogão solar do tipo parabólico e fogão solar do tipo caixa. Destarte, o vigente trabalho concentra-se na comparação de dois protótipos de fogões solares, um do tipo parabólico e outro do tipo caixa. É oportuno ressaltar que este último é confeccionado a partir de materiais de baixo custo, tais como: papelão, chapa metálica, vidro, cola e um material refletor (papel alumínio). A estrutura consiste basicamente em duas caixas sobrepostas uma dentro da outra, isoladas entre si e fechada com vidro, como denota a Figura 1.

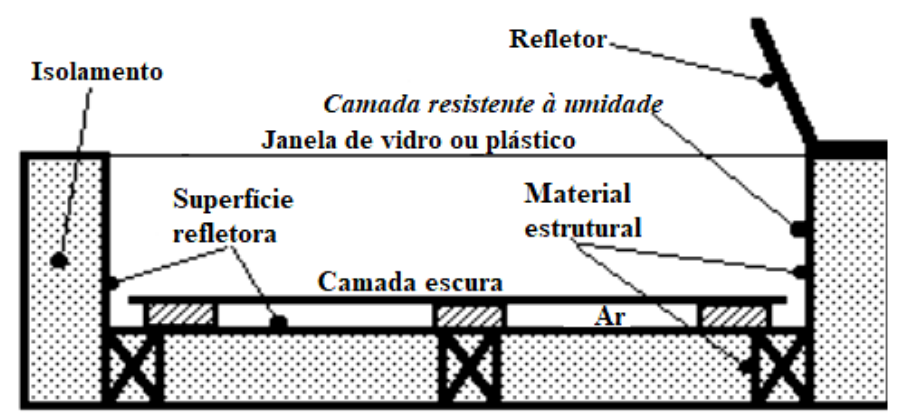

FIGURA 1. Esquema de perfil de um fogão solar do tipo caixa. Adaptado de [8]

A caixa interna, conta com uma placa metálica escura no fundo e suas laterais com algum material reflexivo, há também o uso opcional de um refletor externo [8]. O uso do material refletor possibilita a passagem de raios solares, facilitando à concentração de calor no interior da estrutura e, por conseguinte, a cocção dos alimentos, tendo em vista que para uma maior absorção de calor, recomenda-se pintar o fundo do fogão na cor preta ou revesti-la com uma chapa de metal. Aliado a isso, além da facilidade no processo de montagem, sua utilização consiste basicamente em posicionar a panela no interior do fogão, pelo qual a radiação incide e possibilita o processo de cozimento do alimento. 
Conforme [7], pode-se destacar as seguintes vantagens em relação a utilização de fogões solares do tipo caixa: o cozimento solar não envolve nenhuma despesa periódica no combustível já que a energia solar é totalmente gratuita. Nesse caso, percebe-se uma boa relação custo-benefício, dada pela economia do combustível convencional (lenha ou GLP). Estima-se que por meio do uso regular desse modelo, pode-se economizar cerca de 3 a 4 cilindros de GLP por ano; reduz-se o tempo, haja vista que não necessita estar presente para o acompanhamento do cozimento; não há riscos de queimar a comida; proporciona-se alimentos mais nutritivos devido ao seu cozimento ser de forma mais lenta; durabilidade e simplicidade no manuseio, além de não poluir o meio ambiente, visto que não ocorre a liberação de gases de efeito estufa no processo de cocção dos alimentos.

Acrescenta-se também o fato de que o fogão solar pode alvejar excelentes resultados concernentes a eficiência térmica, já que segundo [9] a eficiência térmica de fogões solares do tipo caixa encontra-se normalmente entre 30 e 50\%. Não obstante, a estimativa de [10] salientou que a eficiência térmica desse modelo se aproxima de $20 \%$. Contudo, segundo [11] a eficiência do protótipo pode chegar a $30 \%$, se porventura os fogões solares conterem refletores multipasso. No entanto, segundo [12] diversos fatores, incluindo o acesso a materiais de baixo custo, disponibilidade de combustíveis tradicionais para cozinhar, clima, preferências culinárias, localização geográfica, razões culturais e capacidade técnica, afetam drasticamente a aproximação das pessoas a utilização da tecnologia de cozimento solar.

Por outro lado, segundo [4] o fogão solar do tipo parabólico possui um dispositivo óptico (refletor) entre a fonte de radiação e a superfície absorvedora. Nesse viés, a área da superfície absorvedora é menor do que a área do dispositivo de captação da energia solar, de modo a aumentar a intensidade energética. Assim, o fogão solar parabólico é composto por um refletor, geralmente espelhos ou adesivos de papel alumínio distribuídos em uma superfície de forma côncava com alto grau de polimento e uma estrutura de metal para comportar a face refletora.

De acordo com [1], suas principais características são: a temperatura no foco pode chegar a $350^{\circ} \mathrm{C}$ ou mais, dependendo do tamanho da parabólica refletora; tempo de aquecimento rápido, se comparado com os outros modelos de fogões solares; necessita de luz solar direta; faz-se essencial um mecanismo de acompanhamento da trajetória do sol com reorientação, usualmente a cada 30 minutos; apresenta um esfriamento repentino do alimento se houver desvio de foco ou nebulosidade acentuada; alguns são instáveis à ventos; risco de fogo ou queimaduras; danos aos usuários devido aos raios refletidos e ao fato de ficar exposto ao sol. Para fogões concentradores primeiramente tem-se o processo de reflexão dos raios solares e sua concentração em um ponto focal no fundo da panela. A energia radiante concentrada no material será em parte refletida e o restante absorvida em forma de calor, sendo transmitido para a panela pelo processo de transferência de calor, como evidencia a Figura 2.

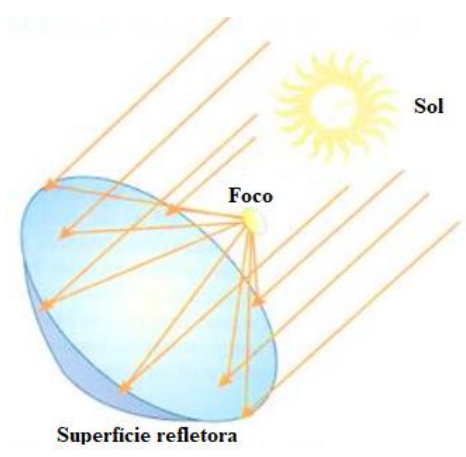

FIGURA 2. Princípio de funcionamento do fogão solar do tipo parabólico. Adaptado de [13]

De acordo com [14], em 1960 um estudo da ONU foi publicado para avaliar as reais possibilidades de implantação e desenvolvimento das cozinhas solares nos países subdesenvolvidos e em desenvolvimento. A conclusão dessa publicação foi que as cozinhas eram viáveis e que era preciso apenas uma mudança nos hábitos para uma adaptação à sua utilização em grande escala. Sabe-se que a tecnologia dos fornos solares condiria não somente em países dos continentes Asiáticos e Africanos, mas sim em todo o globo. Por exemplo, no Brasil, segundo [6] no sertão nordestino assolado pela seca, o sertanejo sofre com a fome e a sede devido à inclemência do sol sobre suas terras áridas. O uso de fogões solares na caatinga se torna uma opção para amenizar essa situação possibilitando ao sertanejo uma melhor condição de vida 


\section{MATERIAIS E MÉTODOS}

No intuito de demonstrar a tecnologia de cocção de alimentos através da conversão direta da energia luminosa dos raios solares em energia térmica, realizou-se a montagem de dois protótipos de fogões solares, um do tipo caixa e outro do tipo parabólico. Nesse viés, objetivando tornar os fogões viáveis economicamente, utilizou-se materiais de baixo custo e ou reaproveitados para a confecção dos mesmos, como por exemplo, uma caixa de papel ofício do tipo A4, retalhos de madeira e uma antena parabólica de internet que havia sido descartada.

Ademais, almejando obter uma maior confiabilidade e eficiência no processo de cocção dos alimentos, usou-se alguns equipamentos de medições, tais como um termômetro infravermelho e um piranômetro digital. Os termômetros infravermelhos são sensores capazes de aferir a temperatura de corpos ou superfícies através da energia radiante emitida por eles, assim a medição da temperatura é feita de modo que o sensor não precisa tocar a superfície. Por outro lado, o piranômetro mede a irradiância global (direta somada à difusa) em W/m².

Nesse contexto, para o dimensionamento do sistema térmico dos fogões solares limitou-se o diâmetro das panelas em 18 centímetros, visto que para o fogão solar parabólico quanto menor for a base da panela, maior será a incidência solar que chega à superfície refletora. Desta forma, a escolha do recipiente adequado é fundamental, uma vez que o mesmo irá influenciar significativamente no desempenho do sistema. Por conseguinte, verificou-se as dimensões da antena parabólica e calculou-se a máxima potência térmica fornecida, que é diretamente proporcional a área útil do concentrador. Por outro lado, para o fogão solar tipo caixa determinou-se a potência fornecida fundamentado nas dimensões de uma caixa de papel ofício do tipo A4. Para intensificar o isolamento térmico do sistema, colocou-se isopor em toda área de contato com a caixa interna e, seguidamente, recobriu-se com papel alumínio, otimizando, dessa forma, a superfície de reflexão e a eficiência térmica do fogão.

Para a fabricação do fogão solar tipo caixa utilizou-se uma caixa de papel ofício do tipo A4; uma bobina de papel alumínio; uma folha de isopor com espessura de $40 \mathrm{~mm}$; uma chapa metálica com geometria retangular reaproveitada e uma tampa de vidro reutilizada de outro fogão solar construído no âmbito da universidade. Nesse sentido, o custo médio do protótipo ficou em torno de R\$24,00. Já para a confecção do fogão solar parabólico foram reutilizados retalhos de madeira de uma construção civil; uma antena de internet em desuso; alguns pregos e parafusos; duas fitas metálicas empregadas na manutenção de ar-condicionado, bem como um tubo e uma barra de ferro utilizados para a confecção do suporte da panela, que foram reaproveitados de uma sucata. Por questões estéticas, os protótipos foram pintados com uma lata de tinta spray, mitigando, dessa maneira, a ação dos intemperes da natura. O custo médio do fogão solar parabólico foi aproximadamente $\mathrm{R} \$$ 20,00. É oportuno ressaltar, que os custos mencionados anteriormente referem-se somente aos dos materiais, visto que não foi terceirizado nenhuma etapa da confecção dos fogões, sendo tudo realizado pelos autores do projeto.

Nos testes de temperatura do foco do fogão solar parabólico, as medições foram realizadas exatamente no ponto onde a reflexão dos raios solares era mais intensa, pelo qual configurou-se manualmente para o centro da base da panela. Em contrapartida, no fogão solar do tipo caixa as medições concernentes à temperatura foram executadas no interior da caixa, onde localiza-se o recipiente. Dessa maneira, espera-se que em um dia ensolarado o desempenho teórico do fogão solar do tipo parabólico seja superior ao fogão solar do tipo caixa, haja vista que o mesmo apresenta uma maior potência útil, o que catalisa o processo de cocção do alimento.

Nesse sentido, fez-se uma análise comparativa do desempenho entre os protótipos no processo de cocção de duas porções de arroz com aproximadamente 80 gramas cada uma, levando em consideração as observações concernentes aos valores de temperatura, a irradiância e ao tempo de cozimento. Dessa maneira, as verificações foram realizadas no âmbito da UFERSA, nas proximidades do Laboratório de Engenharia I das 10:35hs às 14:05hs, variando as medições em intervalos de 15 minutos. As Figuras 3 e 4 evidenciam os dois protótipos em pleno funcionamento. 


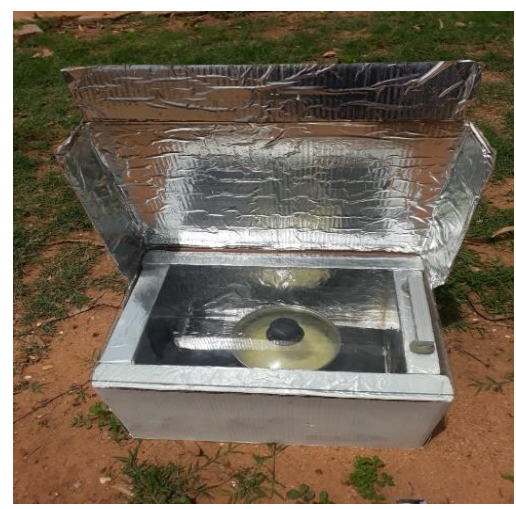

FIGURA 3. Fogão solar do tipo caixa. (Autoria própria)

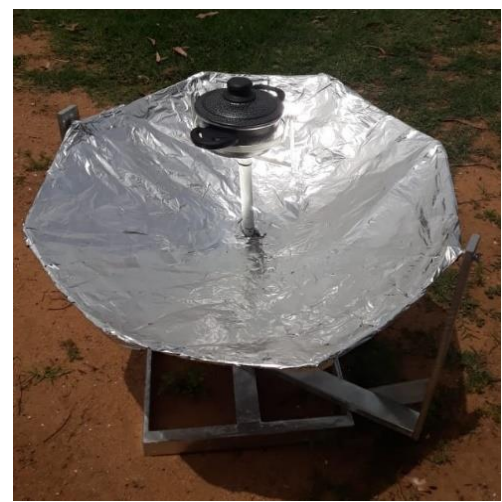

FIGURA 1. Fogão solar do tipo parabólico. (Autoria própria)

\section{RESULTADOS E DISCUSSÕES}

Fundamentado nas observações referentes aos valores de temperatura e ao tempo de cozimento entre os modelos de fogões solares estudados, foi possível confeccionar os gráficos de eficiência relativos ao processo de cozimento das porções de arroz tanto no fogão solar do tipo parabólico quanto no fogão solar do tipo caixa. Ademais, fez-se um estudo do clima, medindo-se a irradiância a cada 15 minutos. No período de ensaio, observou-se uma nebulosidade acentuada, ou seja, o sol estava parcialmente coberto pelas nuvens, comprometendo, dessa forma, o desempenho dos protótipos. A Figura 5 representa o gráfico do clima no período das observações, das 10:35hs às 14:05hs.

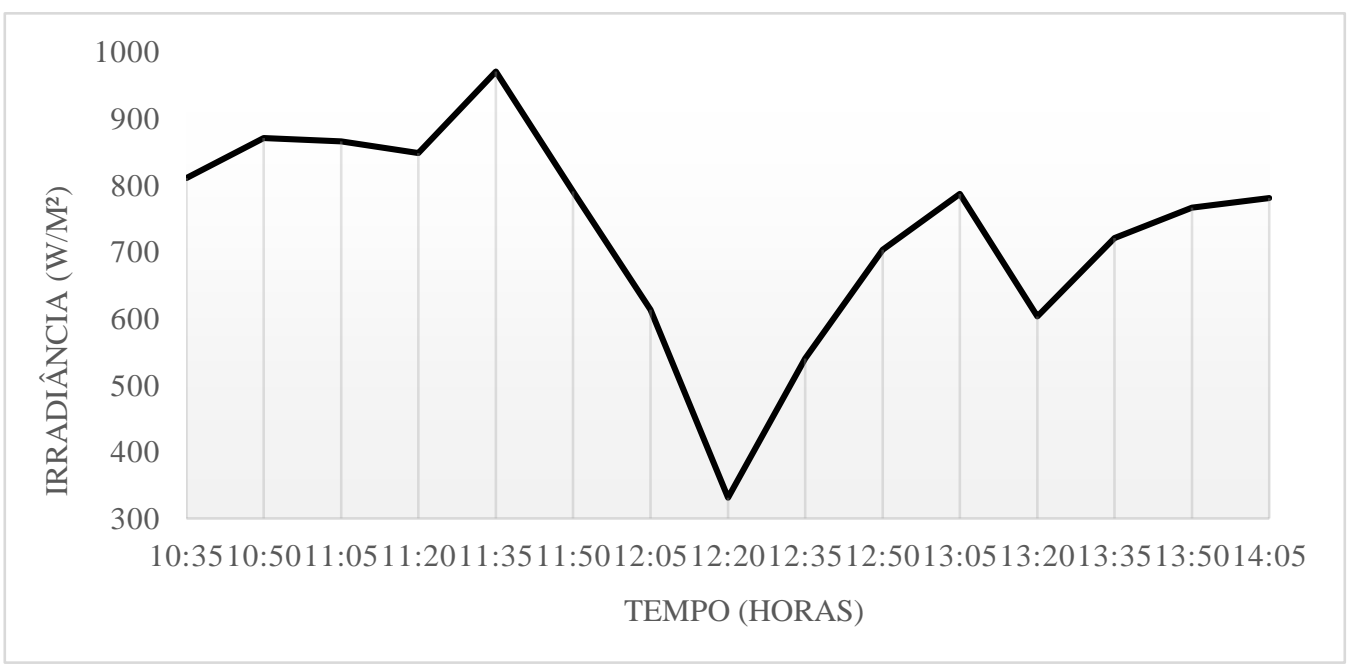

FIGURA 5- Comportamento da irradiação no período de cocção do arroz nos fogões solares. (Autoria própria) 
Em relação à eficiência do protótipo do fogão solar do tipo parabólico, observou-se que, em um dia nebuloso, este modelo se mostrou menos eficiente quando comparado aos demais tipos de fogões solares. Nesse sentido, sua eficiência é diretamente proporcional a irradiância solar, ou seja, pode ser afetada consideravelmente pela instabilidade do clima.

Em contrapartida, percebeu-se nitidamente uma melhor eficiência do fogão solar do tipo caixa, uma vez que, seu formato de caixa auxilia na formação de uma atmosfera ao redor do alimento que provocará o efeito estufa, funcionando como um forno comum e acelerando o processo de cocção. Nesse contexto, o fogão solar tipo caixa tem melhor desempenho em um dia nebuloso. As Figuras 6 e 7 ilustram, respectivamente, os valores de temperatura na região focal do fogão solar parabólico, ou seja, onde localiza-se a panela, bem como a eficiência térmica do fogão solar do tipo caixa em função do tempo de cocção do alimento.

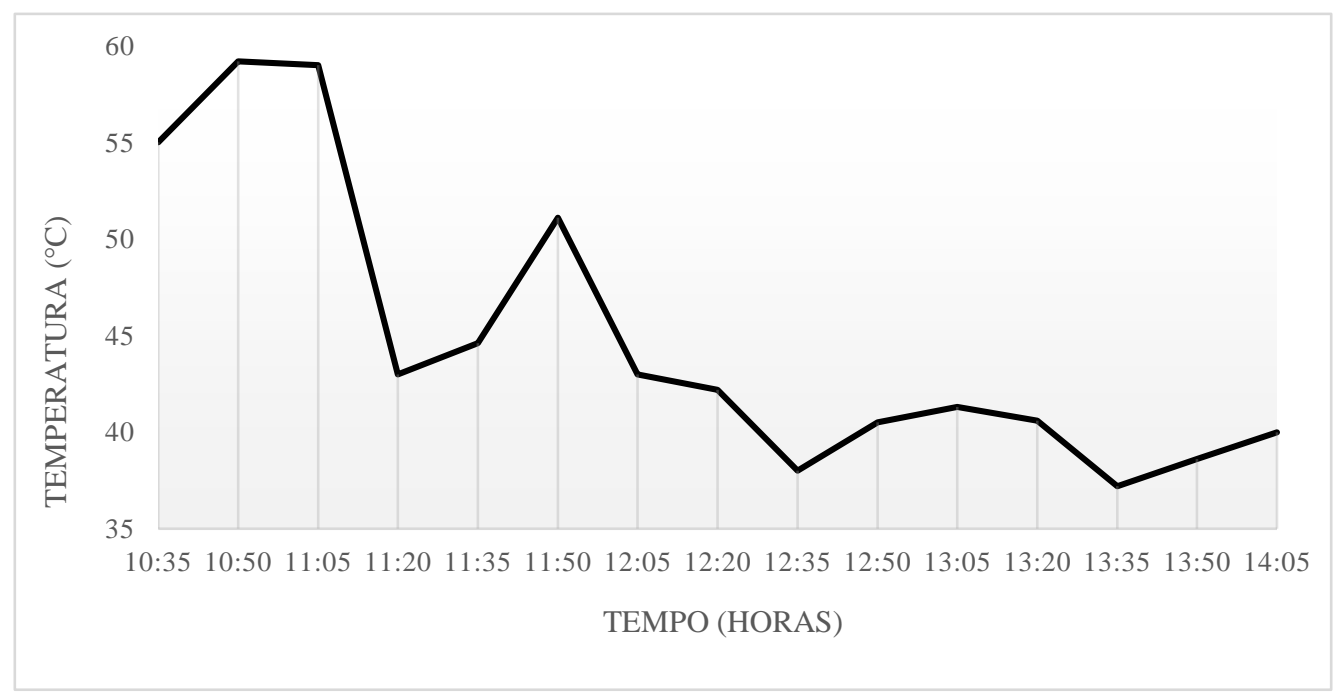

FigURA 6. Eficiência térmica do fogão solar do tipo parabólico. (Autoria própria)

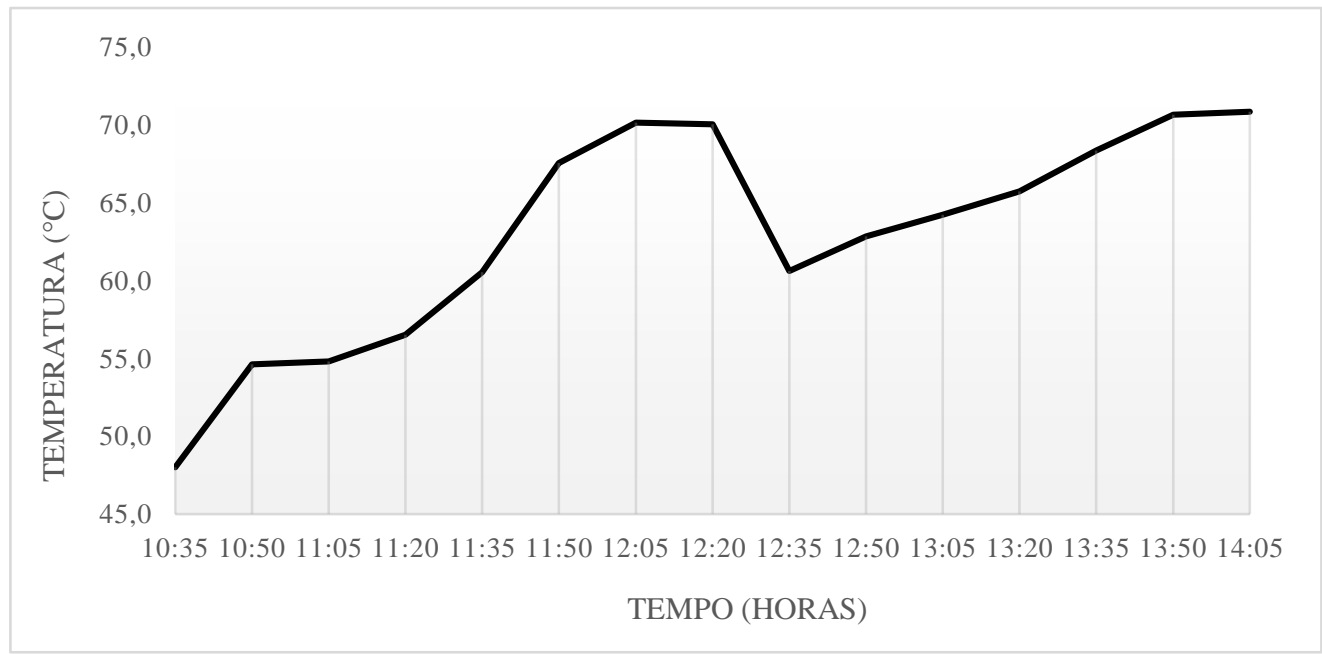

FIGURA 7. Eficiência térmica do fogão solar do tipo caixa. (Autoria própria)

É possível notar, nas Figuras 6 e 7, que a nebulosidade afeta significativamente o desempenho dos fogões solares, especialmente a eficiência térmica do fogão solar do tipo parabólico. Assim, em um dia pouco ensolarado, como foi o caso deste estudo, o fogão solar do tipo caixa apresenta um melhor desempenho no processo de cozedura dos alimentos. A Figura 8 denota uma análise comparativa da eficiência térmica entre os dois protótipos. 


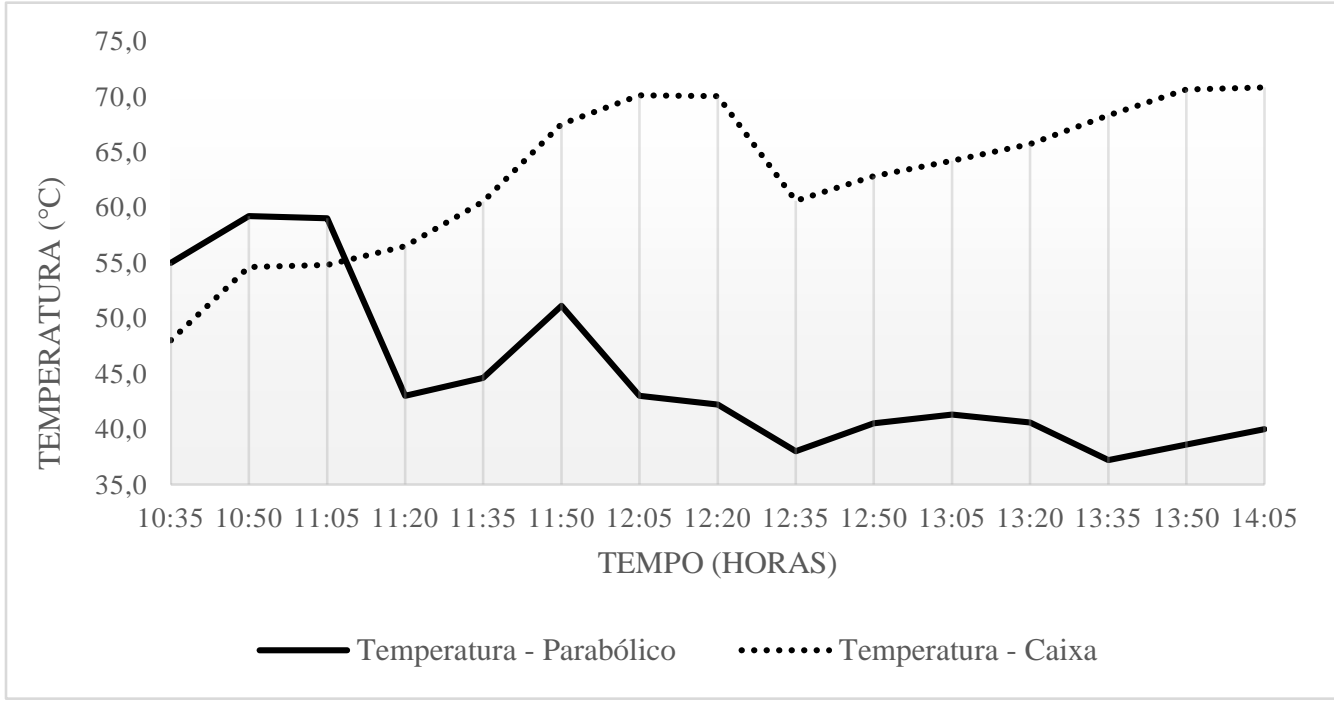

FIGURA 8. Análise comparativa da eficiência térmica entre o fogão solar do tipo parabólico e o fogão solar do tipo caixa. (Autoria própria)

É imprescindível salientar que, em virtude dos efeitos oriundos da nebulosidade, as porções de arroz não foram totalmente cozidas. No entanto, a porção de arroz do fogão solar do tipo caixa foi a que mais se aproximou do ponto ideal de cozimento, uma vez que a temperatura se manteve mais estável nesse modelo. A Figura 9 evidencia a porção de arroz praticamente cozida no fogão solar do tipo caixa.

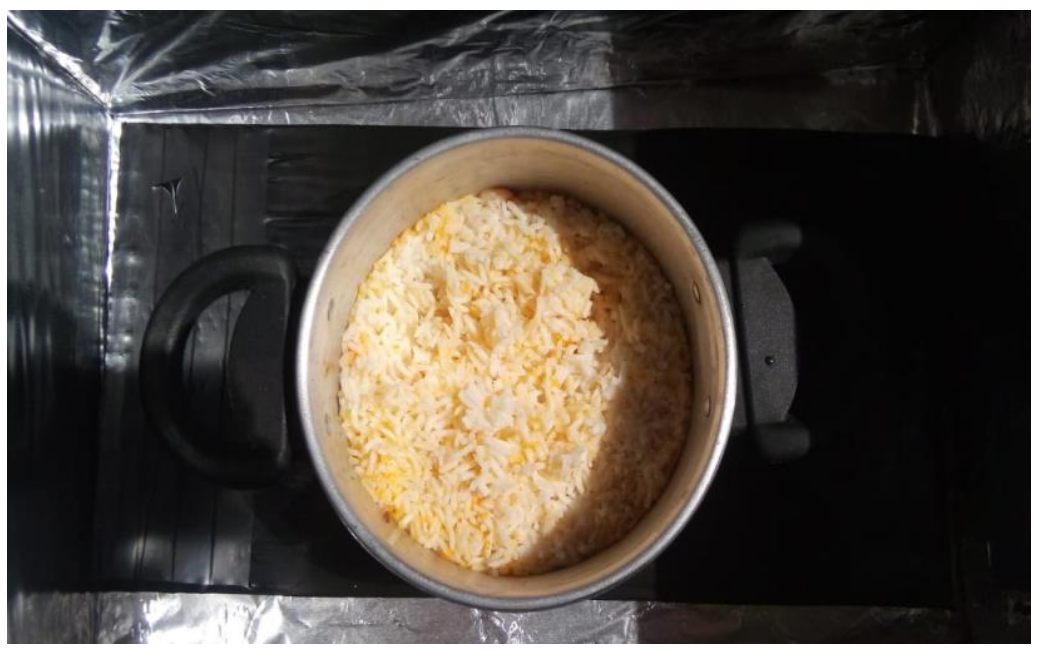

FIGURA 9. Cocção da porção de arroz no fogão solar do tipo caixa. (Autoria própria)

\section{CONCLUSÃO}

No presente estudo, em níveis de comparação, os fogões solares do tipo caixa e do tipo parabólico foram expostos às mesmas condições climatológicas, ambos sendo testados no mesmo intervalo de tempo. Dessa forma, verificou-se ao final do processo que o fogão solar do tipo caixa se sobressaiu em relação ao parabólico, apresentando uma temperatura máxima de $72,5^{\circ} \mathrm{C}$. Esse fato pode ser justificado pela escassez da irradiação no dia da realização do experimento, pelo qual em alguns momentos o tempo permanecia totalmente nublado, dificultando a performance do fogão do tipo parabólico, ou seja, fazendo com que o mesmo não alcançasse temperaturas suficientes para a cocção do alimento, se estabilizando em torno de $42{ }^{\circ} \mathrm{C}$.

Em termos de viabilidade econômica, os fogões solares mostraram-se bem acessíveis, haja vista que a confecção dos mesmos pode ser feita boa parte utilizando materiais recicláveis de baixo custo, como foi o caso do presente estudo, o que contribui significativamente para a disseminação da tecnologia do cozimento solar. Como já havia sido mencionado na seção 3 deste trabalho, o fogão solar do tipo caixa e o fogão solar do tipo 
parabólico teve um custo aproximado de $R$ \$ 24 e $R$ \$ 20, respectivamente, com o material que não pôde ser reaproveitado, mas sim adquirido no mercado nacional.

Nesse sentido, configura-se como uma excelente opção a utilização de fogões e fornos solares em algumas regiões do semiárido nordestino, visto que são áreas privilegiadas no que se refere ao recurso solar, e vale destacar também a simplicidade de confecção dos protótipos desenvolvidos utilizando material reaproveitável que seriam descartados. Aliado a isso, faz-se imprescindível a adoção de políticas públicas de incentivo por parte do governo relacionadas à confecção, ao manuseio e a utilização dessa tecnologia, destacando a sua importância tanto para a sociedade quanto para a preservação do meio ambiente.

\section{REFERÊNCIAS}

[1] RAMOS FILHO, R. E. B. Análise de desempenho de um fogão solar construído a partir de sucatas de antena de TV. 2011.96 f. Dissertação (Mestrado em Engenharia Mecânica) - Universidade Federal do Rio Grande do Norte, Natal, 2011.

[2] VARELLA, F. K. de O. M. Estimativa do Índice de Nacionalização dos Sistemas Fotovoltaicos no Brasil. 2009. 148 f. Tese (Doutorado em Planejamento de Sistemas Energéticos). Comissão de Pós-graduação em Engenharia Mecânica - Universidade Estadual de Campinas, São Paulo, 2009.

[3] SOUZA, L. G. M. Viabilidades térmica, econômica e de materiais da utilização de tubos de PVC como elementos absorvedores em coletores de um sistema de aquecimento de água por energia solar. Tese (Doutorado em Ciência e Engenharia de Materiais). Programa de Doutorado em Ciência e Engenharia de Materiais - Universidade Federal do Rio Grande do Norte, Natal, 2002.

[4] SANTOS, C. V.; FERRARETTO, T. R. G. Fogão solar: ferramenta viável para cozimento de alimentos a partir de materiais de baixo custo. Extensio: Revista Eletrônica de Extensão, Universidade Federal de Santa Catarina, Florianópolis, v.12. n. 21. P. 97-104, 2016.

[5] WORLD ENERGY OUTLOOK. International Energy Agency, 2006. Disponível em: <https://www.iea.org/weo/ >. Acesso em: 09 mar. 2019.

[6] SOUZA, R. F. Viabilidade de uso de um fogão solar para cocção de alimentos com parábola refletora fabricada em compósito que utiliza fibras de Carnaúba e resina Ortoftálica. 2014. 78 f. Dissertação (Mestrado em Tecnologia de Materiais; Projetos Mecânicos; Termociências) - Universidade Federal do Rio Grande do Norte, Natal, 2014.

[7] AADIWAL, R.; HASSANI, M.; KUMAR, P. An Overview Study of Solar Cookers, International Research Journal of Engineering and Technology - IRJET, v.4, p.3-5. 2017. 